\title{
Monocrotaline-induced liver toxicity in rat predicted by a combined in vitro physiologically based kinetic modeling approach
}

\author{
Suparmi Suparmi ${ }^{1,2}$ (D) Sebastiaan Wesseling ${ }^{1} \cdot$ Ivonne M. C. M. Rietjens $^{1}$
}

Received: 6 December 2019 / Accepted: 28 May 2020 / Published online: 9 June 2020

(c) The Author(s) 2020

\begin{abstract}
The aim of the present study was to use an in vitro-in silico approach to predict the in vivo acute liver toxicity of monocrotaline and to characterize the influence of its metabolism on its relative toxic potency compared to lasiocarpine and riddelliine. In the absence of data on acute liver toxicity of monocrotaline upon oral exposure, the predicted dose-response curve for acute liver toxicity in rats and the resulting benchmark dose lower and upper confidence limits for $10 \%$ effect $\left(\mathrm{BMDL}_{10}\right.$ and $\mathrm{BMDU}_{10}$ ) were compared to data obtained in studies with intraperitoneal or subcutaneous dosing regimens. This indicated the predicted $\mathrm{BMDL}_{10}$ value to be in line with the no-observed-adverse-effect levels (NOAELs) derived from availabe in vivo studies. The predicted $\mathrm{BMDL}_{10}-\mathrm{BMDU}_{10}$ of $1.1-4.9 \mathrm{mg} / \mathrm{kg}$ bw/day also matched the oral dose range of 1-3 mg PA/kg bw/ day at which adverse effects in human are reported. A comparison to the oral toxicity of the related pyrrolizidine alkaloids (PAs) lasiocarpine and riddelliine revealed that, although in the rat hepatocytes monocrotaline was less toxic than lasiocarpine and riddelliine, due to its relatively inefficient clearance, its in vivo acute liver toxicity was predicted to be comparable. It is concluded that the combined in vitro-PBK modeling approach can provide insight in monocrotaline-induced acute liver toxicity in rats, thereby filling existing gaps in the database on PA toxicity. Furthermore, the results reveal that the kinetic and metabolic properties of PAs can vary substantially and should be taken into account when considering differences in relative potency between different PAs.
\end{abstract}

Keywords Monocrotaline $\cdot$ Acute toxicity $\cdot$ Liver $\cdot$ PBK modeling $\cdot$ Reverse dosimetry

$\begin{array}{ll}\text { Abbreviations } \\ \text { AIC } & \text { Akaike information criterion } \\ \text { ALT } & \text { Alanine aminotransferase } \\ \text { BMD }_{10} & \begin{array}{l}\text { Benchmark dose resulting in a } 10 \% \text { effect } \\ \text { above background level }\end{array} \\ \text { BMDL }_{10} & \begin{array}{l}\text { Lower confidence limit of the } \text { BMD }_{10} \\ \text { BMDU }_{10}\end{array} \\ \text { Upper confidence limit of the BMD } \\ \text { EFSA } & \text { European Food Safety Authority } \\ \text { GI } & \text { Gastrointestinal }\end{array}$

Electronic supplementary material The online version of this article (https://doi.org/10.1007/s00204-020-02798-z) contains supplementary material, which is available to authorized users.

Suparmi Suparmi

s.suparmi@wur.nl; suparmi@unissula.ac.id

1 Division of Toxicology, Wageningen University and Research, Stippeneng 4, 6708 WE Wageningen, The Netherlands

2 Department of Biology, Faculty of Medicine, Universitas Islam Sultan Agung, Jl. Raya Kaligawe KM 4, Semarang 50112, Indonesia

\begin{tabular}{|c|c|}
\hline GSH & Glutathione \\
\hline HPC & Hepatic parencymal cells \\
\hline HVOD & Hepatic veno-occlusive disease \\
\hline $\mathrm{Ka}$ & $\begin{array}{l}\text { Absorption rate for uptake from the GI tract } \\
\text { compartment into the liver }\end{array}$ \\
\hline PAs & Pyrrolizidine alkaloids \\
\hline PBK & Physiologically based kinetic \\
\hline POD & Point of departure \\
\hline NOAEL & No observed adverse effect level \\
\hline LOAEL & Lowest observed adverse effect level \\
\hline pRPF & Provisional relative potency factors \\
\hline 3Rs & Replacement, reduction and refinement \\
\hline
\end{tabular}

\section{Introduction}

Monocrotaline (Fig. 1) is a secondary metabolite that belongs to a group of cyclic di-ester 1,2-unsaturated pyrrolizidine alkaloids (PAs). It is naturally present in Crotalaria species including Crotalaria spectabilis, C. sagittalis L., C. retusa L., and C. aegyptiaca Beth (Adams and Rogers 

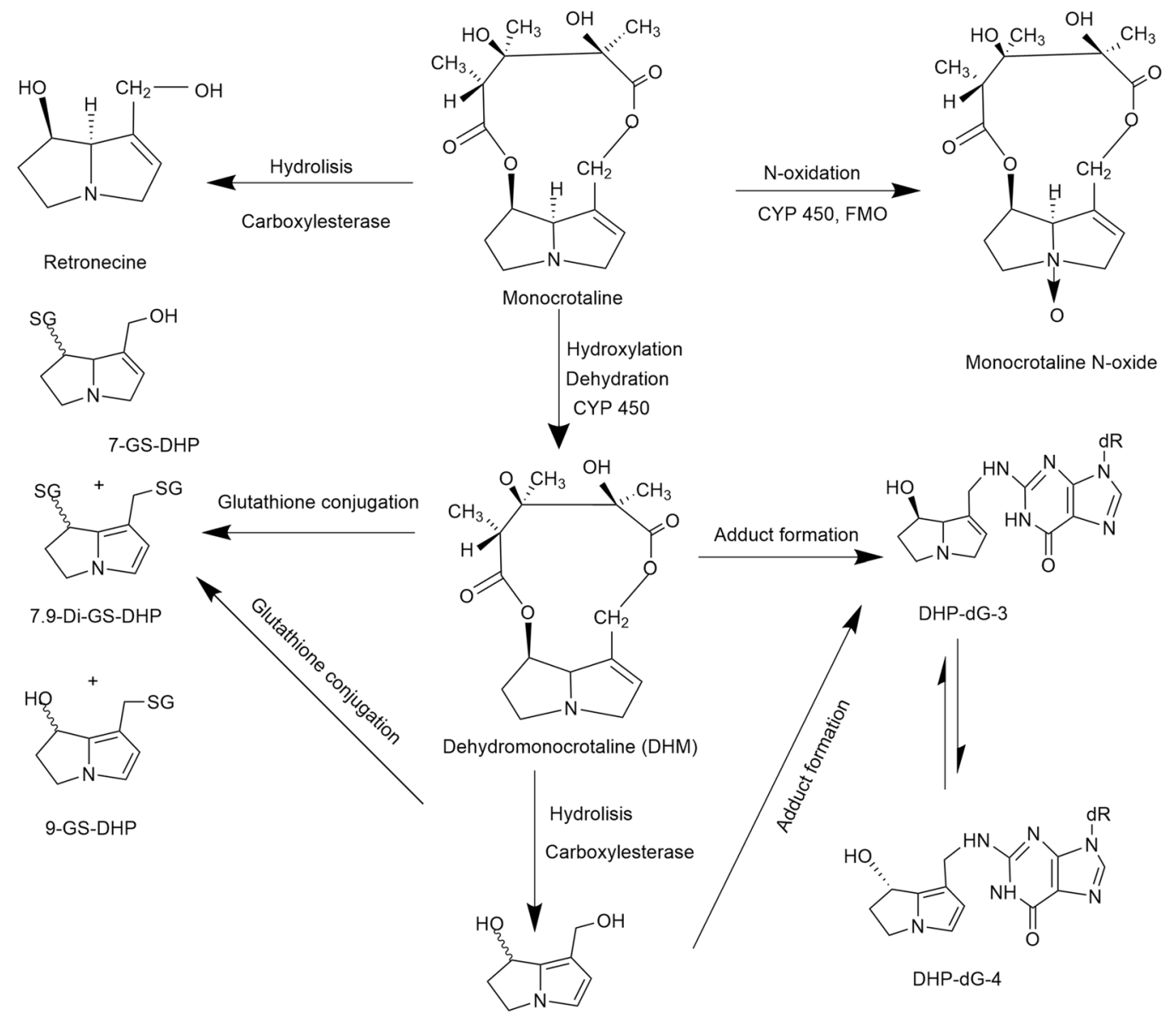

Dehydropyrrolizidine

Fig. 1 Schematic diagram of the metabolic pathways of monocrotaline and DNA adduct formation by monocrotaline metabolites relevant for rat and human (Wang et al. 2009; Xia et al. 2018; Yang et al.

1939; EFSA 2011). High acute toxicity of monocrotaline towards animals and humans has been reported (Copple et al. 2002, 2004; Lachant et al. 2018; Yan and Huxtable 1995). Recently EFSA (2017) listed monocrotaline as one of the 17 PAs to be monitored for their presence in food and feed because of possible concern for human health related to exposure to these PAs via food including consumption of tea and herbal infusions. PAs including monocrotaline are of concern because of their hepatotoxicity and the fact that they are genotoxic carcinogens (EFSA 2017). Monocrotaline is categorized as being possibly carcinogenic in humans (category 2B) (IARC 2019).

Like all 1,2-unsaturated PAs monocrotaline is a protoxin (unreactive compound) requiring hepatic metabolic activation by cytochromes P450 to exert hepatic toxicity and carcinogenicity (Mattocks 1968; Shumaker et al. 1976). CYP2A6 and CYP2E1 were found to be the major $\mathrm{P} 450$ s active in metabolic activation of monocrotaline in
2017; Yao et al. 2014). FMO=flavin-containing monooxygenase, CYP $450=$ cytochromes $\mathrm{P} 450$

rat and human liver (Ruan et al. 2014; Yao et al. 2014). The expression of CYP2A6 in human liver accounts for $\sim 4 \%$ of total hepatic CYPs, whereas in rats, the CYP2A family including CYP2A6 accounts for 2\% (Martignoni et al. 2006). Also, the species differences in CYP2A6 activity between rats and human liver microsomes in inducing liver toxicity have been reported to be negligible (Pearce et al. 1992). Furthermore, the expression and activity of CYP2E1 in human have been reported to be $80 \%$ identical to that in rat (Martignoni et al. 2006), and, therefore, rats may be an appropriate model to study CYP2E1-dependent metabolism in human (Zuber et al. 2002). This is further supported by the fact that rats and human liver microsomes displayed qualitatively similar activation and detoxification activities in incubations with monocrotaline (Couet et al. 1996; Geburek et al. 2019). Metabolism of PAs is generally occurring via three pathways, namely hydrolysis, $\mathrm{N}$-oxidation, and hydroxylation followed by dehydrogenation (Fig. 1) (Fu 
et al. 2004). Upon this dehydrogenation, an unstable and highly reactive intermediate, named dehydromonocrotaline is formed. Dehydromonocrotaline can react with cellular macromolecules including proteins and DNA to form protein and DNA adducts, which are considered to be responsible for the toxicity including the genotoxicity of monocrotaline (Butler et al. 1970; Lafranconi and Huxtable 1984; Reid et al. 1998). Alternatively, dehydromonocrotaline can be detoxified through hydrolysis resulting in 6,7-dihydro7-hydroxy-1-hydroxymethyl-5H-pyrrolizidine (DHP) and via glutathione (GSH) conjugation resulting in formation of GSH-DHP and di-GSH-DHP (Fig. 1). These molecules are considered less toxic and more stable (Fu et al. 2004; Li et al. 2016), although they may still also react with proteins and DNA to form the same DNA adducts formed by dehydromonocrotaline and DHP (Xia et al. 2018).

Upon bioactivation, monocrotaline causes a variety of toxic insults including pulmonary endothelial apoptosis, acute lung injury, pulmonary fibrosis, necrotizing pulmonary arteritis, myocarditis, hepatic veno-occlusive disease (HVOD), pulmonary hypertension, and right ventricular hypertrophy (Fu 2017; Gomez-Arroyo et al. 2012; Li et al. 2011; Lu et al. 2018; Schultze and Roth 1998; Shumaker et al. 1976), in addition to an increased risk of developing liver carcinomas (Newberne and Rogers 1973). In human, acute exposure to PAs can cause HVOD with severe liver damage with in some cases fatal outcomes (Mohabbat et al. 1976; Tandon et al. 1976), whereas chronic exposure is considered to increase the risk of developing cancer (EFSA 2017).

However, only for a limited number of 1,2-unsaturated PAs in vivo toxicity data are available, and this implies that alternative testing strategies including read across and in vitro to in vivo extrapolation (IVIVE) become important. In previous studies, we reported the development and evaluation of physiologically based kinetic (PBK) models for the PAs lasiocarpine and riddelliine for rat and human, and their use for conversion of in vitro data for toxicity in primary hepatocytes to quantitatively predict in vivo acute liver toxicity for both rat and human (Chen et al. 2018; Ning et al. 2019). Marked differences in toxicokinetics were observed between these two PAs influencing the predicted in vivo toxicity. This importance of toxicokinetics in the relative differences in toxic potency between different PAs was also noted in a recent study that characterized the intrinsic relative potency of a series of PAs showing a role for the rate and extent of their metabolism (Lester et al. 2019). The aim of the present study was to use the in vitro-PBK modelfacilitated reverse dosimetry approach to predict the in vivo acute liver toxicity of monocrotaline and to characterize the influence of its metabolism on its relative toxic potency compared to lasiocarpine and riddelliine. Monocrotaline was selected as the model compound because this is one of the few PAs in addition to lasiocarpine and riddelliine for which in vivo data on kinetics and liver toxicity are available, thus enabling evaluations of the PBK model and predictions made.

\section{Materials and methods}

\section{Chemicals and biological materials}

Monocrotaline (>98\%) was purchased from MedChemExpress (Huissen, The Netherlands). The plateable cryopreserved male rat (Sprague-Dawley) hepatocytes (RTCP10 ${ }^{\mathrm{TM}}$ ), the thawing and plating supplement (serum-containing, $\mathrm{CM}$ 3000) pack, the cell maintenance supplement pack (serum free, CM4000), and Williams E Medium without phenol red (WEM, A1217601) were purchased from ThermoFisher (Naarden, The Netherlands). Pooled liver and intestinal microsomes from male Sprague-Dawley rats were purchased from Xenotech (Lenexa, USA). Dimethyl sulfoxide (DMSO) was obtained from Acros Organics (Geel, Belgium). Acetonitrile (UPLC/MS grade) was obtained from Biosolve (Valkenswaard, The Netherlands). Potassium hydrogen phosphate $\left(\mathrm{K}_{2} \mathrm{HPO}_{4}\right)$ and trifluoroacetic acid (TFA) were purchased from Merck (Darmstadt, Germany). Fetal calf serum (FCS) and the reduced form of $\beta$-nicotinamide adenine dinucleotidephosphate sodium salt hydrate (NADPH) were obtained from Sigma-Aldrich (Zwijndrecht, The Netherlands). WST-1 (4-[3-(4-iodophenyl)-2-(4-nitrophenyl)-2H-5-tetrazolio]1,3-benzene disulfonate) solution was purchased from Roche (Woerden, The Netherlands). Rapid equilibrium dialysis (RED) devices were purchased from Thermo Fisher Scientific (Bleiswijk, The Netherlands). Phosphate-buffered saline (PBS) was obtained from Invitrogen (Breda, The Netherlands).

\section{Outline of the PBK modeling-facilitated reverse dosimetry approach}

The prediction of in vivo monocrotaline-induced liver toxicity in rat using a combined in vitro-PBK modeling approach consisted of the following steps: (1) establishment of an in vitro concentration-response curve for the toxicity of monocrotaline in primary rat hepatocytes, (2) development of a PBK model describing in vivo kinetics of monocrotaline, using kinetic parameters defined based on in vitro assays using rat liver and intestinal samples, (3) evaluation of the PBK model predictions against available literature data on dose-dependent blood levels of monocrotaline, (4) translation of the in vitro concentration-response curve for acute liver toxicity into an in vivo dose-response curve for acute liver toxicity in rat using the PBK model, taking into acount differences in protein binding of monocrotaline in the 
in vitro and in vivo situation, (5) benchmark dose (BMD) analysis on the predicted in vivo dose-response data to obtain a point of departure (POD), and (6) evaluation of the predicted POD for liver toxicity against available literature data.

\section{In vitro liver toxicity assay with primary rat hepatocytes}

The monocrotaline-induced liver toxicity was tested in vitro using the WST-1 assay which measures the formazan formation by the metabolically active cells from WST-1. Pooled cryopreserved plateable male rat (Sprague-Dawley) hepatocytes (RTCP10 $10^{\mathrm{TM}}$ ) were thawed and seeded in accordance with the manufacturer's protocol. Briefly, cells were seeded in 96-well plates (Greiner bio-one, Alphen aan den Rijn, The Netherlands) at a concentration of $5 \times 10^{5} \mathrm{cells} / \mathrm{ml}$ to give $1.25 \times 10^{4}$ cells/well and incubated at $37{ }^{\circ} \mathrm{C}, 5 \% \mathrm{CO}_{2}$ in a humidified atmosphere for $6 \mathrm{~h}$ to allow cell adherence. After incubation, medium was aspirated and then replaced by $100 \mu \mathrm{l} /$ well of exposure medium (serum free) containing the required concentration of monocrotaline. The cells were incubated for $24 \mathrm{~h}$ at increasing concentrations $(0-600 \mu \mathrm{M})$ of monocrotaline in exposure medium added from 200 times concentrated stock solutions in DMSO. The solvent DMSO $(0.5 \%(\mathrm{v} / \mathrm{v})$ final concentration in exposure medium) was used as a negative control and triton $\mathrm{X}$ (final concentration $1 \%(\mathrm{v} / \mathrm{v})$ in exposure medium) served as a positive control in all cytotoxicity assays. After exposure for $24 \mathrm{~h}, 5 \mu \mathrm{l}(1: 20$ dilution) WST-1 reagent was added to each well and plates were incubated for an additional $1 \mathrm{~h}$. Then, the plate was shaken at $1000 \mathrm{rpm}$ for $1 \mathrm{~min}$, and absorbance was measured at $440 \mathrm{~nm}$ (background absorbance at $620 \mathrm{~nm}$ was subtracted) using a SpectraMax M2 (Molecular Devices, Sunnyvale, USA).

Data are presented as mean values \pm SE from three independent experiments with three different batches of rat hepatocytes. The cell viability was expressed as percentage of the solvent control, with the solvent control set at $100 \%$. The obtained concentration-response curves for hepatotoxicity were fitted with a symmetrical sigmoidal model (Hill slope) which was further used to derive $\mathrm{IC}_{50}$ values using $\log$ [inhibitor] vs. normalized response using GraphPad Prism software (version 5.00 for Windows, GraphPad software, San Diego, USA).

\section{In vitro incubations of monocrotaline with rat liver and intestinal microsomes to derive the kinetic parameters for the PBK model}

The kinetic parameters for the PBK model of monocrotaline in rats were estimated by a substrate depletion approach using the protocol for microsomal incubations reported by Wang et al. (2009) with little modifications. The liver microsomal incubations were carried out in a total volume of $100 \mu \mathrm{l}$ containing $0.1 \mathrm{M} \mathrm{K}_{2} \mathrm{HPO}_{4}(\mathrm{pH} 7.4), 0.5 \mathrm{mg}$ protein/ml of pooled rat liver/ intestinal microsomes, and monocrotaline at final concentrations ranging from 0 to $500 \mu \mathrm{M}$ (added from 100 times concentrated stock solutions in $0.1 \mathrm{M} \mathrm{HCl}$, the latter in line with the protocol of Wang et al. (2009), and shown to have no effect on the incubation $\mathrm{pH})$. After $5 \mathrm{~min}$ of pre-incubation in a shaking water bath at $37^{\circ} \mathrm{C}$, the reactions were started by the addition of $1 \mathrm{mM}$ NADPH. The reactions were carried out for $1 \mathrm{~h}$ and $2 \mathrm{~h}$ for liver and intestinal microsomes, respectively. For each incubation, a corresponding control incubated in the absence of NADPH was included by adding buffer instead of NADPH. To stop the metabolic conversion, $100 \mu \mathrm{l}$ of ice-cold methanol was added and the sample was put on ice, then centrifuged at $5000 \times \mathrm{g}$ for $20 \mathrm{~min}$ at $4{ }^{\circ} \mathrm{C}$ using a microcentrifuge (CT15RE, VWR, Leuven, Belgium). Supernatants were diluted 200 times in $90 \%$ (v/v) acetonitrile and transferred to LC-MS vials. LC-MS analysis was performed using a Shimadzu Nexera XR LC-20AD SR UPLC system in tandem with a Shimadzu LCMS-8040 mass spectrometer (Shimadzu, Kyoto, Japan). From each incubation, $1 \mu \mathrm{l}$ of supernatant was loaded onto a Luna Omega polar C18 $100 \mathrm{~A}$ LC column $(1.6 \mu \mathrm{m} 100 \times 2.1 \mathrm{~mm}$, Phenomenex $)$ fitted with a FP polar precolumn (Phenomenex), using a flow rate of $0.3 \mathrm{ml} / \mathrm{min}$. The temperature was set at $40{ }^{\circ} \mathrm{C}$ and $5{ }^{\circ} \mathrm{C}$ for column and sample, respectively. The mobile phase consisted of ultrapure water (solvent A) and acetonitrile (solvent $\mathrm{B})$ both containing $0.1 \%(\mathrm{v} / \mathrm{v})$ formic acid. The gradient began with $100 \%$ solvent A ( $0 \%$ B) for 1 min to wash away unwanted salts, followed by a linear gradient from 0 to $5 \% \mathrm{~B}$ till $8 \mathrm{~min}$ and a further increase to $100 \% \mathrm{~B}$ in $2 \mathrm{~min}$, keeping the elution at $100 \%$ B for $0.5 \mathrm{~min}$, then the column was set back to the starting conditions and equlibrated for $3.4 \mathrm{~min}$ before the next injection. The concentration of monocrotaline in the samples was quantified using a calibration curve prepared using a commercially available standard. For all incubations, three independent replicates were performed.

The time-dependent decrease in the concentration of monocrotaline detected in NADPH-containing reaction mixtures corrected for the time-dependent decrease in the concentration of monocrotaline in the corresponding controls without the cofactor NADPH was used to determine the rate of monocrotaline depletion. The data for the monocrotaline concentration-dependent rate of monocrotaline depletion thus obtained were fitted to the standard Michaelis-Menten equation (Eq. 1) using GraphPad Prism, 5.0 software (San Diego, CA, USA).

$$
V=\frac{V_{\max } \times[S]}{\left(K_{\mathrm{m}}+[S]\right)},
$$


with $[S]$ representing the monocrotaline concentration, $V_{\max }$ being the apparent maximum velocity ( $\mathrm{nmol} / \mathrm{min} / \mathrm{mg}$ microsomal protein), and $K_{\mathrm{m}}$ being the apparent Michaelis-Menten constant $(\mu \mathrm{M})$. The ratio of $V_{\max }$ and $K_{\mathrm{m}}$ was calculated as the in vitro catalytic efficiency $\left(k_{\text {cat }}\right)$ expressed in $\mathrm{nmol} / \mathrm{min} / \mathrm{g}$ tissue. The rat microsomal protein yield of $35 \mathrm{mg}$ microsomal protein/g tissue and $20.6 \mathrm{mg}$ microsomal protein/g tissue for liver and small intestine, respectively (Cubitt et al. 2009; Medinsky et al. 1994) were used to scale $V_{\max }$ and $k_{\text {cat }}$ values obtained from the in vitro microsomal incubations to in vivo $V_{\max }$ and $k_{\text {cat }}$ values expressed in $\mathrm{nmol} / \mathrm{min} / \mathrm{g}$ tissue and $\mathrm{ml} / \mathrm{min} / \mathrm{g}$ tissue, respectively. The rat liver weight of $8.5 \mathrm{~g}$ and small intestine weight of $3.5 \mathrm{~g}$ (see Table 1) (Brown et al. 1997) were used to scaled the in vivo $k_{\text {cat }}$ values to values expressed in $\mathrm{ml} / \mathrm{min} / \mathrm{tissue}$.

\section{Determination of fraction unbound $\left(f_{u b}\right)$ of monocrotaline in rat serum and correction for protein binding}

The monocrotaline-induced liver toxicity is assumed to be dependent on the concentration of unbound monocrotaline available for bioactivation. To correct for the difference in protein binding in the in vitro incubations and the in vivo situation, the fraction unbound $\left(f_{\mathrm{ub}}\right)$ of monocrotaline in the in vitro and in vivo situations was determined. Since the in vitro toxicity was determined in serum-free assay medium, the concentrations of monocrotaline tested were considered to be equal to the unbound concentration in the assay $\left(f_{\text {ub,in vitro }}=1.0\right)$. The $f_{\text {ub,in vivo }}$ was determined by rapid equilibrium dialysis (RED) (Waters et al. 2008). Briefly, $200 \mu \mathrm{l}$ of spiked rat serum containing $150 \mu \mathrm{M}$ monocrotaline (final concentration, $0.5 \% \mathrm{v} / \mathrm{v}$ DMSO) was added to the serum chambers of the RED device insert, while $350 \mu \mathrm{l}$ dialysis buffer (PBS) was added to the buffer chamber. The device was sealed with tape and incubated at $37{ }^{\circ} \mathrm{C}$ on a shaker at $250 \mathrm{rpm}$. After incubation for $5 \mathrm{~h}$ when the system reached equilibrium (van Liempd et al. 2011), $50 \mu \mathrm{l}$ of postdialysis samples was collected from the serum and buffer chambers into separate eppendorf tubes. Subsequently, $50 \mu \mathrm{l}$ of rat serum was added to the buffer samples and $50 \mu$ of PBS was added to the serum samples. To precipitate the protein, $300 \mu \mathrm{l}$ of ice-cold acetonitrile $(90 \% \mathrm{v} / \mathrm{v})$ was added to both tubes. After putting the mixtures on ice for $30 \mathrm{~min}$, the mixtures were centrifuged at $15,000 \mathrm{~g}$ for $30 \mathrm{~min}$ at $4{ }^{\circ} \mathrm{C}$, and the supernatants were diluted five times in $90 \%(\mathrm{v} / \mathrm{v})$ acetonitrile and analyzed by LC-MS as described above. The measurements were performed in triplicate.

The concentration of monocrotaline detected in each chamber was used to calculate $f_{\text {ub,in vivo }}$ using Eq. 2 (van Liempd et al. 2011; Waters et al. 2008). The value of $f_{\text {ub, in vivo }}$ was used in the PBK modelling-based reverse dosimetry to calculate the
Table 1 Physiological and physicochemical parameters for rats applied in the PBK model for monocrotaline, lasiocarpine and riddelliine

\begin{tabular}{lll}
\hline Parameters & Symbol & Value \\
\hline Physiological parameters (Brown et al. 1997) & & \\
Body weight (kg) & BW & 0.25 \\
Tissue volume (fraction of body weight) & & \\
Fat & VFc & 0.07 \\
Liver & VLc & 0.034 \\
Small intestine & VSic & 0.014 \\
Blood & VBc & 0.074 \\
Richly perfused tissue & VRc & 0.042 \\
Slowly perfused tissue & VSc & 0.75 \\
Cardiac output (L/h/kg.74) & QC & 15 \\
Blood flow to tissue (fraction of cardiac output) & & \\
Fat & QFc & 0.07 \\
Liver & QLc & 0.132 \\
Small intestine & QSic & 0.118 \\
Richly perfused tissue & QRc & 0.51 \\
Slowly perfused tissue & QSc & 0.17
\end{tabular}

Physicochemical parameters (DeJongh et al. 1997)

Tissue/blood partition coefficients

Monocrotaline

\begin{tabular}{lll} 
Fat & PF & 0.46 \\
Liver & PL & 0.77 \\
Small intestine & PI & 0.77 \\
Richly perfused tissue & PR & 0.77 \\
Slowly perfused tissue & PS & 0.42 \\
Lasiocarpine (Chen et al. 2018) & & \\
Fat & PF & 2.44 \\
Liver & PL & 0.88 \\
Small intestine & PI & 0.88 \\
Richly perfused tissue & PR & 0.88 \\
Slowly perfused tissue & PS & 0.48 \\
Riddelliine (Chen et al. 2018) & & \\
Fat & PF & 0.44 \\
Liver & PL & 0.77 \\
Small intestine & PI & 0.77 \\
Richly perfused tissue & PR & 0.77 \\
Slowly perfused tissue & PS & 0.43 \\
\hline
\end{tabular}

total concentration of monocrotaline in rat liver blood according to the Eq. 3.

$f_{\mathrm{ub}, \text { in vivo }}=\frac{C_{\mathrm{b}}}{C_{\mathrm{s}}}$,

$C_{\text {monocrotaline, rat blood }}=\frac{C_{\mathrm{ub}, \text { in vitro }}}{f_{\mathrm{ub}, \text { in vivo }}}$, 
where $f_{\text {ub,in vivo }}$ represents the fraction unbound of monocrotaline in rat serum, $C_{\mathrm{b}}$ is the concentration of monocrotaline in the buffer chamber $(\mu \mathrm{M}), C_{\mathrm{s}}$ is the concentration of monocrotaline detected in the serum chamber $(\mu \mathrm{M})$, $C_{\text {monocrotaline, rat blood }}$ is the total concentration of monocrotaline in rat blood $(\mu \mathrm{M}), C_{\mathrm{ub}, \text { in vitro }}$ is the unbound concentration of monocrotaline in the in vitro culture medium which in the present study equals the concentration tested because $f_{\text {ub,in vitro }}$ equals 1.0.

\section{Development and evaluation of a PBK model for monocrotaline in rat}

A PBK model for monocrotaline in rat was developed based on the models for lasiocarpine and riddelliine in rats (Chen et al. 2018). Figure 2 depicts the conceptual PBK model, which consists of seven separate compartments connected via the blood circulation. The physiological and anatomical parameters for rats were obtained from literature (Brown et al. 1997), while the blood/tissue partition coefficients for monocrotaline were estimated using the formula reported by (DeJongh et al. 1997) based on the water/octanol partition coefficient (log Kow) of monocrotaline of -0.65 predicted by ChemDraw 18.1 (PerkinElmer, USA) as presented in Table 1.

The absorption rate for uptake from the GI tract compartment into the liver $\mathrm{Ka}$ ) of monocrotaline was estimated based on the reported Ka for adonifoline (Wang et al. 2011), using the correlation of Caco-2 permeation and molecular properties described in literature (Hou et al. 2004), as follows:

$\log P_{\text {app }}=-5.469+0.236 \log P$,

$\mathrm{Ka}_{\text {monocrotaline }}=\frac{\log P_{\text {app monocrotaline }} \times \mathrm{Ka}_{\text {adonifoline }}}{\log P_{\text {app adonifoline }}}$,

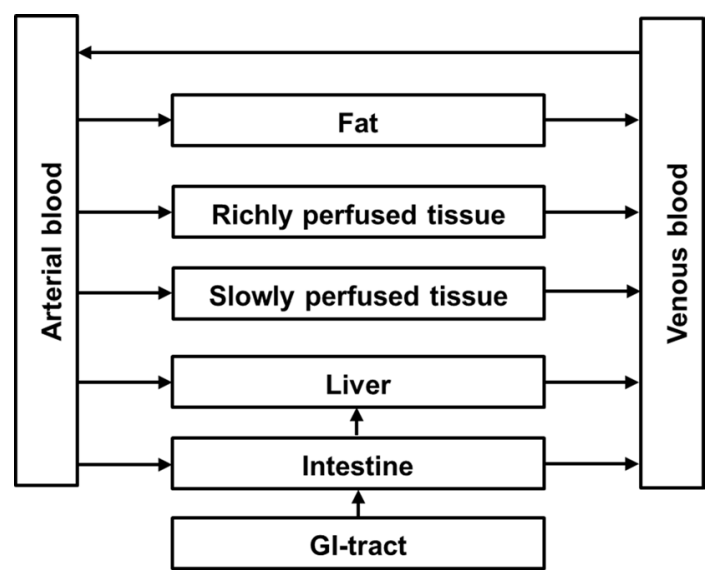

Fig. 2 Schematic diagram of the PBK model for monocrotaline in rat, based on the model previously developed for lasiocarpine and riddelliine (Chen et al. 2018) where $\log P_{\text {app }}$ is the $\log$ value of the permeability coefficient $\left(P_{\text {app }}\right), \log P$ is the water/octanol partition coefficient predicted by ChemDraw 18.1 (Perkin-Elmer, USA) being -0.65 and -1.49 for monocrotaline and adonifoline, respectively. The $\log P_{\text {app monocrotaline }}$ and $\log P_{\text {app adonifoline }}$ calculated by Eq. 4 are -5.62 for monocrotaline and -5.82 for adonifoline. Using the reported Ka for adonifoline of $0.6 / \mathrm{h}$, the value of Ka for monocrotaline derived from Eq. 5 is $0.58 / \mathrm{h}$. This Ka value was assumed to reflect efficient uptake of monocrotaline via passive diffusion. Tu et al. (2013) reported that the organic cation transporter 1 (OCT1) plays a role in active transport of monocrotaline into the liver. The substrates of OCT1 are known to be mainly organic cations, while some weak bases, non-charged compounds and anions are also transported (Koepsell and Endou 2004). Retronecine-type PAs including monocrotaline and retrorsine were also shown to be high affinity substrates of OCT1 (Tu et al. $2013,2014)$. At low $\mathrm{pH}$, where monocrotaline is protonated to its corresponding cation transport by OCT1 is dominant and passive diffusion is almost abolished (Tu et al. 2013). At higher $\mathrm{pH}$ values in the intestinal compartment (Evans et al. 1988; McConnell et al. 2008), a substantial part of monocrotaline will be neutral and transported via passive diffusion. The data of Tu et al. (2013) indicate that in rat hepatocytes at $\mathrm{pH}$ 7.4, OCT1-mediated transport and passive diffusion may contribute equally. Thus, to take this OCT1-mediated transport into account, the Ka value as obtained from Eq. 5 for passive diffusion was multiplied by 2 to include the extra uptake via OCT1.

Furthermore, the data presented by Tu et al. (2013) provide an overall rate for uptake of monocrotaline into primary rat hepatocytes amounting to $14.5 \mathrm{pmol} / \mathrm{mg}$ protein/min at $2 \mu \mathrm{M}$ monocrotaline and $\mathrm{pH}$ 7.4. Using scaling factors of $120 \mathrm{mg}$ protein/g liver and $34 \mathrm{~g}$ liver $/ \mathrm{kg}$ bw results in a rate for uptake of monocrotaline in the liver of rats of $3.55 \mu \mathrm{mol} / \mathrm{h} / \mathrm{kg}$ bw. Using the Ka value of $1.16 / \mathrm{h}$ at a dose level of $1 \mathrm{mg} / \mathrm{kg}$ bw and the formula for uptake into the liver now used in the PBK model: ka (in $/ \mathrm{h}) \times$ AGI (in $\mu \mathrm{mol} / \mathrm{h} / \mathrm{kg}$ bw) results in a rate for uptake into the liver that equals $3.57 \mu \mathrm{mol} / \mathrm{h} / \mathrm{kg}$ bw. This further supports that the use of the Ka of $1.16 / \mathrm{h}$ adequately models the overall uptake of monocrotaline in the liver.

The model code in Berkeley Madonna (version 9.1.14, UC Berkeley, CA, USA) using Rosenbrock's algorithms for stiff systems for the developed PBK models of monocrotaline in rats is presented in supplementary materials 1. In the PBK model, the excretion of monocrotaline into urine was not included due to the fact that the excretion of monocrotaline as a parent compound in urine is negligible (Bull et al. 1968). 


\section{Evaluation of the PBK model}

To evaluate the PBK model performance, predicted monocrotaline concentrations in blood were compared to reported concentrations of monocrotaline equivalents in rat blood upon intravenous (iv) injection of $60 \mathrm{mg} / \mathrm{kg}$ bw $(10 \mu \mathrm{Ci} /$ $\mathrm{kg}$ ) of $\left[{ }^{14} \mathrm{C}\right]$ monocrotaline (Estep et al. 1991). To this end, the predicted time-dependent monocrotaline concentration in blood was compared to the time-dependent monocrotaline equivalent concentration curve reported by Estep et al. (1991) which was derived from the published curve of monocrotaline equivalents (in $\mathrm{nmol} / \mathrm{g}$ ) against time (in h) using webPlotDigitizer (https://automeris.io/WebPlotDig itizer/) under the assumption that the weight of blood plasma $(\mathrm{g})$ is equal to the volume of blood $(\mathrm{mL})$, because the blood density was assumed to be $1.0 \mathrm{~g} / \mathrm{ml}$. The final concentration of monocrotaline equivalents $(\mu \mathrm{M})$ in whole blood was obtained by added up the concentration values in plasma and in red blood cells (supplementary materials 2) (Estep et al. 1991).

In addition, a sensitivity analysis was performed to identify the key parameters which contribute most to the predicted maximum concentrations in liver blood at an oral dose of 1 and $3 \mathrm{mg} / \mathrm{kg}$ bw which represent the lowest and highest dose in the range for the estimated daily human intake of PAs reported by EFSA (2017) that might result in adverse health effects if consumed for 4 days up to a 2-week periods.

The sensitivity analysis was performed as described previously (Evans and Andersen 2000) calculating normalized sensitivity coefficients (SCs):

$\mathrm{SC}=\frac{\left(C^{\prime}-C\right)}{P^{\prime}-P} \times\left(\frac{P}{C}\right)$,

where $C$ is the initial value of the model output, $C^{\prime}$ is the modified value of the model output resulting from an increase in parameter value, $P$ is the initial parameter value and $P^{\prime}$ is the modified parameter value. Each parameter was analyzed individually by changing one parameter at a time (5\% increase) and keeping the other parameters the same (Evans and Andersen 2000).

\section{Translation of in vitro liver toxicity to in vivo liver toxicity}

The in vitro concentration-response curve for monocrotalineinduced cytotoxicity in primary rat hepatocytes was translated into a predicted in vivo dose-response curve for acute liver toxicity using PBK modeling-facilitated reverse dosimetry. Within this translation, a correction was made to take the difference in protein binding between the in vitro incubations $\left(f_{\text {ub,in vitro }}=1.00\right)$ and the in vivo situation $\left(f_{\text {ub,in vivo }}\right.$ determined as described above) into account. This was done because it was assumed that only the free fraction of monocrotaline will be available to be bioactivated and exert the effects. Each concentration tested in the cytotoxicity assay, corrected by Eq. 3 to calculate the corresponding total blood concentration, taking differences in in vitro and in vivo protein binding into acount, was set equal to the maximum concentration of monocrotaline in the liver blood and the developed PBK model was used to determine the coresponding oral dose. The dose-response curve for monocrotaline-induced liver toxicity resulting from this translation was compared to the previous predicted dose-response curves for lasiocarpine and riddelliine (Chen et al. 2018).

\section{BMD analysis of in vitro concentration-response data and of predicted in vivo dose-response data}

To define the benchmark dose resulting in a $10 \%$ increase in liver toxicity over the background level $\left(\mathrm{BMD}_{10}\right)$, the predicted in vivo dose-response data for monocrotaline-induced acute liver toxicity in rats were used for BMD modeling. To compare the toxic potency of monocrotaline with that of lasiocarpine and riddelliine, the predicted dose-response curves reported previously for these PAs (Chen et al. 2018) was also used for BMD modeling. Dose-response modeling and BMD analysis were performed using the EFSA BMD modeling webtool (PROAST version 66.38, https://shiny-efsa.openanalytics. eu/app/bmd) (EFSA-Scientific-Committee et al. 2017). The lowest Akaike Information Criterion (AIC) value among the available models was used to judge the the goodness of fit application of the models.

\section{Evaluation of the predicted POD for liver toxicity against available literature data}

The predicted $\mathrm{BMDL}_{10}-\mathrm{BMDU}_{10}$ values of monocrotaline in this study were compared to the PODs derived from in vivo rat acute liver toxicity data on monocrotaline reported in the literature (Copple et al. 2002, 2004; Lachant et al. 2018; Yan and Huxtable 1996). When the data from these in vivo studies were not suitable for BMD analysis due to the limited number of data points and/or insufficient distribution of the data points over the dose-response curves, the no observed adverse effect level (NOAEL) was used for the comparison. When only a lowest observed adverse effect level (LOAEL) was available, the NOAEL was calculated using the LOAEL divided by a factor of 10 (Barnes et al. 1988). 


\section{Results}

\section{Monocrotaline-induced liver toxicity in vitro}

Monocrotaline-induced liver toxicity in primary rat hepatocytes with an $\mathrm{IC}_{50}$ value of $225 \mu \mathrm{M}$ as shown in Fig. 3. The highest concentration of $600 \mu \mathrm{M}$ decreased cell viability by over $60 \%$ while limited solubility prevented testing of higher concentrations and reaching $100 \%$ cytotoxicity. The $\mathrm{EC}_{50}$ obtained for monocrotaline is 20.7 - and

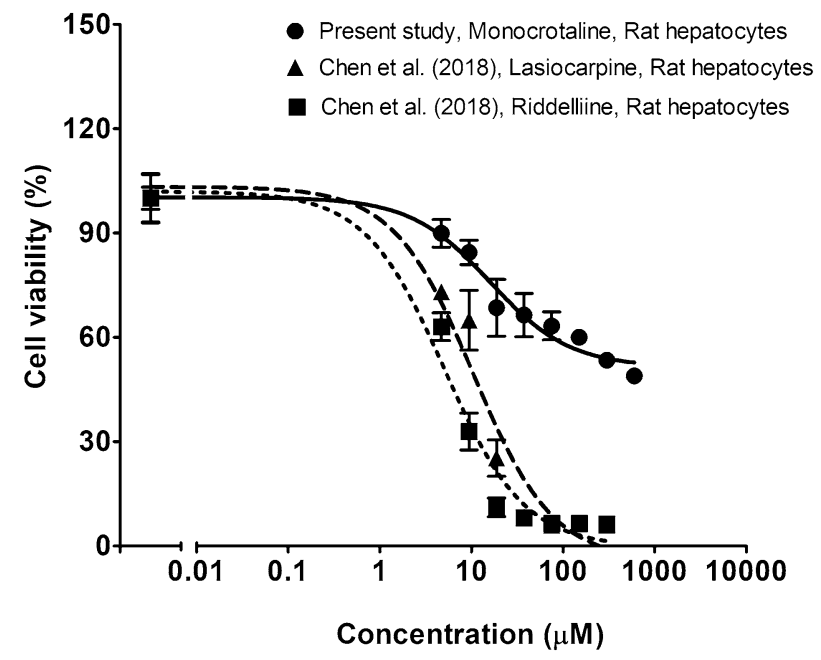

Fig. 3 Concentration-response curves for effects of monocrotaline (circles with solid line) on cell viability of primary rat hepatocytes exposed for $24 \mathrm{~h}$ (means $\pm \mathrm{SE}$ ) and, for comparison, for effects of lasiocarpine (triangles with dashed line) and riddelliine (squares with dotted line) as reported by Chen et al. (2018)

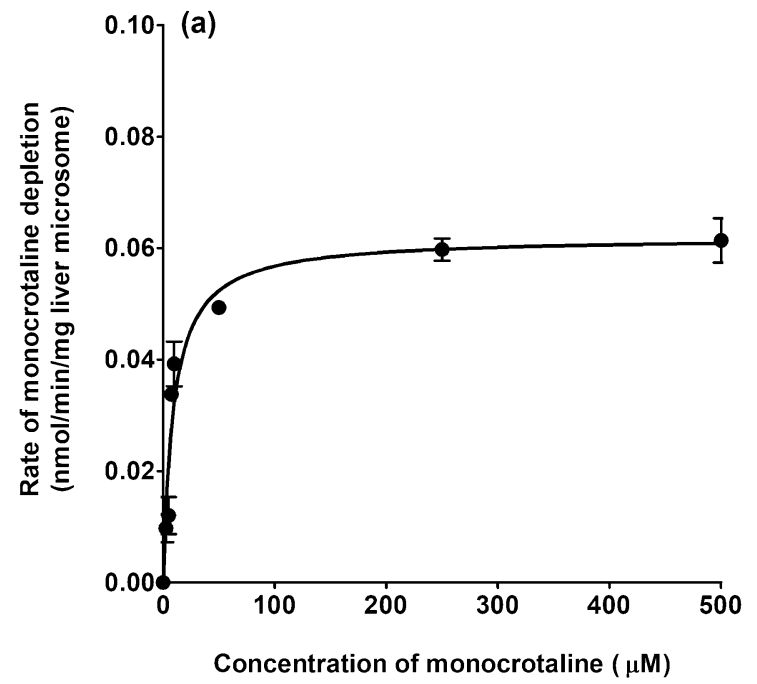

35.7-fold higher than the $\mathrm{EC}_{50}$ values previously obtained in the same model system for lasiocarpine $\left(\mathrm{EC}_{50} 10.9 \mu \mathrm{M}\right)$ and riddelliine $\left(\mathrm{EC}_{50} 6.3 \mu \mathrm{M}\right)$, respectively (Chen et al. 2018).

\section{Metabolic clearance of monocrotaline by rat liver and intestine microsomes}

Figure 4 shows the monocrotaline concentration-dependent rate of conversion of the compound in incubations with rat intestinal and liver microsomes. Table 2 presents the $V_{\max }$ and $K_{\mathrm{m}}$ values derived from these curves and also the catalytic effciency $\left(k_{\text {cat }}\right)$ for clearance of monocrotaline calculated as $V_{\max } / K_{\mathrm{m}}$. For comparison Table 2 also presents the kinetic parameters for depletion of lasiocarpine and riddelliine previously reported (Chen et al. 2018). It appears that monocrotaline is converted by the liver microsomes with an in vivo scaled $k_{\text {cat }}(\mathrm{ml} / \mathrm{min}$ tissue) that is 18 times higher than the conversion rate by intestinal microsomes (Fig. 4 and Table 2). Lasiocarpine and riddelliine showed the same trend where the scaled catalytic efficiency for conversion expressed per intestinal tissue was 15.4 and 253 times, respectively, lower than that for the liver indicating the intestinal contribution to PA clearance to be minor (Table 2). The scaled $k_{\text {cat }}$ for conversion of monocrotaline in the liver was 41.8 and 4.3 times lower compared to the scaled liver $\mathrm{k}_{\mathrm{cat}}$ of lasiocarpine and riddelliine, respectively, indicating that the metabolism of monocrotaline was the lowest among the three PAs. The total scaled in vivo $k_{\text {cat }}$ (sum of liver and intestine) for depletion of monocrotaline was 42.1- and 4.1-fold, respectively, lower than that for lasiocarpine and riddelliine.

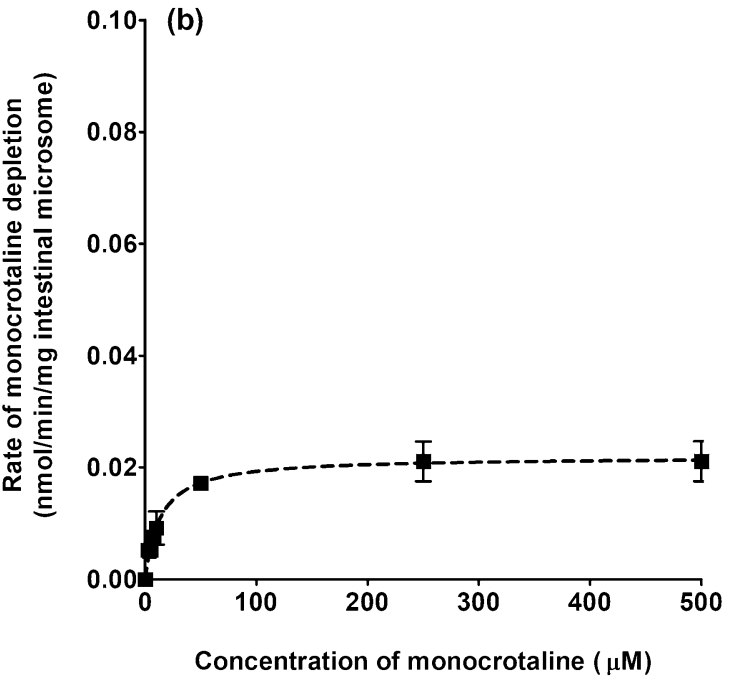

Fig. 4 Concentration-dependent rate of monocrotaline depletion in incubations with: a rat liver microsomes and $\mathbf{b}$ intestinal microsomes. Values are presented as means \pm SE derived from three independent experiments 
Table 2 Kinetic parameters for metabolic conversion of monocrotaline (present study), lasiocarpine and riddelliine (Chen et al. 2018) in incubations with pooled rat liver and intestine microsomes

\begin{tabular}{|c|c|c|c|c|c|c|}
\hline Compound Organ & $\begin{array}{l}V_{\max }(\mathrm{nmol} / \mathrm{min} / \mathrm{mg} \\
\text { microsomal protein })\end{array}$ & $K \mathrm{~m}(\mu \mathrm{M})$ & $\begin{array}{l}k_{\text {cat }}(\mathrm{ml} / \mathrm{min} / \mathrm{mg} \\
\text { microsomal protein })\end{array}$ & $\begin{array}{l}\text { Scaled } V_{\max }(\mathrm{nmol} / \\
\mathrm{min} / \mathrm{g} \text { tissue })^{\mathrm{a}}\end{array}$ & $\begin{array}{l}\text { Scaled } k_{\text {cat }}(\mathrm{ml} / \\
\mathrm{min} / \mathrm{g} \text { tissue })^{\mathrm{a}}\end{array}$ & $\begin{array}{l}\text { Scaled } k_{\text {cat }}(\mathrm{ml} / \\
\mathrm{min} / \text { tissue })^{\mathrm{b}}\end{array}$ \\
\hline \multicolumn{7}{|c|}{ Monocrotaline (present study) } \\
\hline Liver & 0.06 & 9.2 & 0.01 & 2.1 & 0.2 & 1.9 \\
\hline Intestine & 0.02 & 13.4 & 0.001 & 0.4 & 0.03 & 0.1 \\
\hline \multicolumn{7}{|c|}{ Lasiocarpine (Chen et al. 2018) } \\
\hline Liver & 5.3 & 19.5 & 0.27 & 186 & 9.5 & 80.9 \\
\hline Intestine & 1.7 & 23.4 & 0.07 & 35.0 & 1.50 & 5.2 \\
\hline \multicolumn{7}{|c|}{ Riddelliine (Chen et al. 2018) } \\
\hline Liver & 2.1 & 75.7 & 0.03 & 73.5 & 0.97 & 8.2 \\
\hline Intestine & 0.1 & 221 & 0.0005 & 2.06 & 0.009 & 0.03 \\
\hline
\end{tabular}

${ }^{\text {a }}$ Scaled $V_{\max }$ and $k_{\text {cat }}$ calculated from the in vitro $V_{\max }$ and $k_{\text {cat }}$ based on a microsome protein yield of $35 \mathrm{mg}$ microsomal protein/(g liver) or $20.6 \mathrm{mg}$ microsomal protein/(g small intestine) (Cubitt et al. 2009; Medinsky et al. 1994)

${ }^{\mathrm{b}} \mathrm{Scaled}$ in vivo $k_{\text {cat }}(\mathrm{ml} / \mathrm{min} /$ tissue $)$ derived from the in vivo $k_{\text {cat }}(\mathrm{ml} / \mathrm{min} / \mathrm{g}$ tissue $)$ based on the liver weight of $8.5 \mathrm{~g}$ or small intestine weight of $3.5 \mathrm{~g}$ (Brown et al. 1997)

\section{PBK model predictions and evaluation}

Due to unavailability of in vivo kinetic data for monocrotaline upon oral administration in rat, the blood concentration-time curves of monocrotaline as predicted by the developed PBK model upon iv administration were evaluated against the available concentration of monocrotaline equivalents in rat blood upon the iv administration of $60 \mathrm{mg} /$ $\mathrm{kg}$ of $\left[{ }^{14} \mathrm{C}\right]$ monocrotaline (Estep et al. 1991). The predicted blood concentrations were on average 1.6- to 3.4-fold higher than the blood concentrations observed in vivo (see Table S1 supplementary materials 2 ). Given this limited deviation, it was concluded that the PBK model could be used for the in vitro to in vivo extrapolations.

\section{Sensitivity analysis}

The performance of the developed PBK model was further evaluated by a sensitivity analysis to determine the parameters which affect the prediction of the maximum concentration of monocrotaline in liver blood. The parameters that result in a normalized sensitivity coefficient higher than an absolute value of 0.1 are shown in Fig. 5. At an oral dose level of of 1 and $3 \mathrm{mg} / \mathrm{kg}$ bw, representing the lowest and highest dose in the range for the estimated daily human intake of PAs that might result in adverse health effects if consumed for 4 days up to a 2 weeks periods (EFSA 2017), the predicted maximum concentration of monocrotaline in liver blood was affected by the fraction of liver volume (VLc), the partition coefficient of monocrotaline into liver tissue (PL), the partition coefficient into slowly perfused tissue (PS), the absorption rate from the GI tract compartment into the liver $(\mathrm{Ka})$, the liver microsomal protein yield

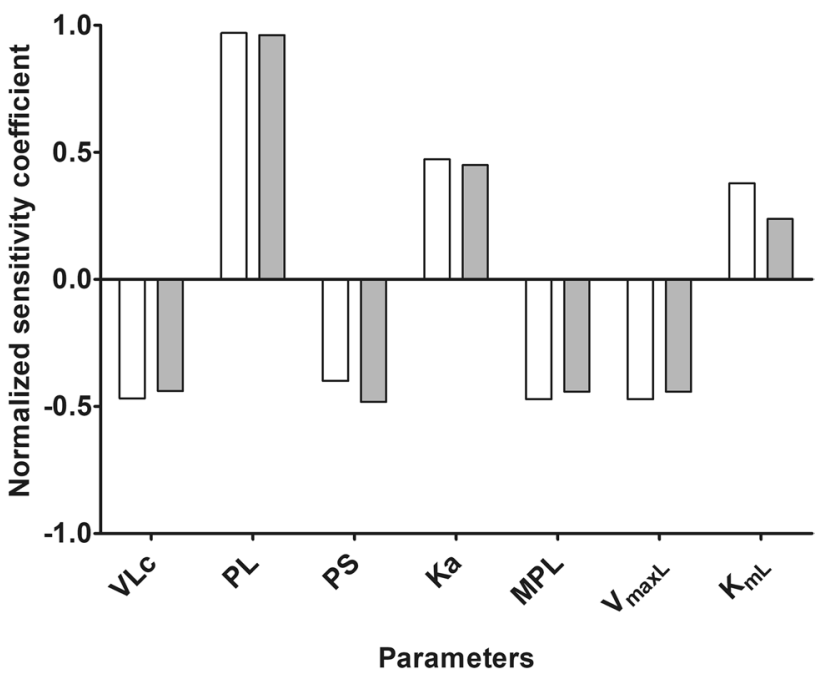

Fig. 5 Normalized sensitivity coefficients for the parameters of the rat PBK model for monocrotaline of influence on the predicted maximum concentration in liver blood at a single oral dose of monocrotaline of $1 \mathrm{mg} / \mathrm{kg}$ bw (white bars), or $3 \mathrm{mg} / \mathrm{kg}$ bw/day (grey bars) PAs. $\mathrm{VLc}=$ fraction of liver volume, $\mathrm{PL}=$ liver/blood partition coefficient, $\mathrm{PS}=$ slowly perfused tissue/blood partition coefficient, $\mathrm{Ka}=$ absorption rate for uptake from the GI tract compartment into the liver, MPL $=$ liver microsomal protein yield, $V_{\operatorname{maxL}}$ and $K_{\mathrm{mL}}=$ the maximum rate of depletion and the Michaelis-Menten constant for depletion of monocrotaline in liver

(MPL), and the kinetic parameters $\left(V_{\operatorname{maxL}}\right.$ and $\left.K_{\mathrm{mL}}\right)$ for monocrotaline depletion in the liver. The predicted monocrotaline concentration in liver blood was not sensitive to the kinetic parameters for monocrotaline depletion in the small intestine-related parameters in line with the earlier observation that monocrotaline metabolism is this organ is substantially less efficient (Fig. 4). 


\section{Predicted hepatotoxicity of monocrotaline in rats and application of PROAST modeling on predicted dose-response data to derive PODs}

The RED assay resulted in an $f_{\mathrm{ub} \text {, in vivo }}$ of monocrotaline in rat serum of $0.53 \pm 0.12$, a value used to correct for the differences in protein binding between the in vivo and in vitro situation. With this $f_{\text {ub,in vivo, }}$, the concentrations tested in the cytotoxicity assay were converted to in vivo total blood concentrations by Eq. 3 and then converted to the corresponding dose levels using the PBK model. The dose levels thus obtained were used to create the corresponding dose-response curve for acute liver toxicity.

The predicted in vivo dose-response curve thus obtained is shown in Fig. 6. For comparison, also the dose-response curves previously predicted for lasiocarpine and riddelliine by the same approach (Chen et al. 2018) are included in the figure. From the results obtained, it can be concluded that monocrotaline is predicted to be somewhat less toxic

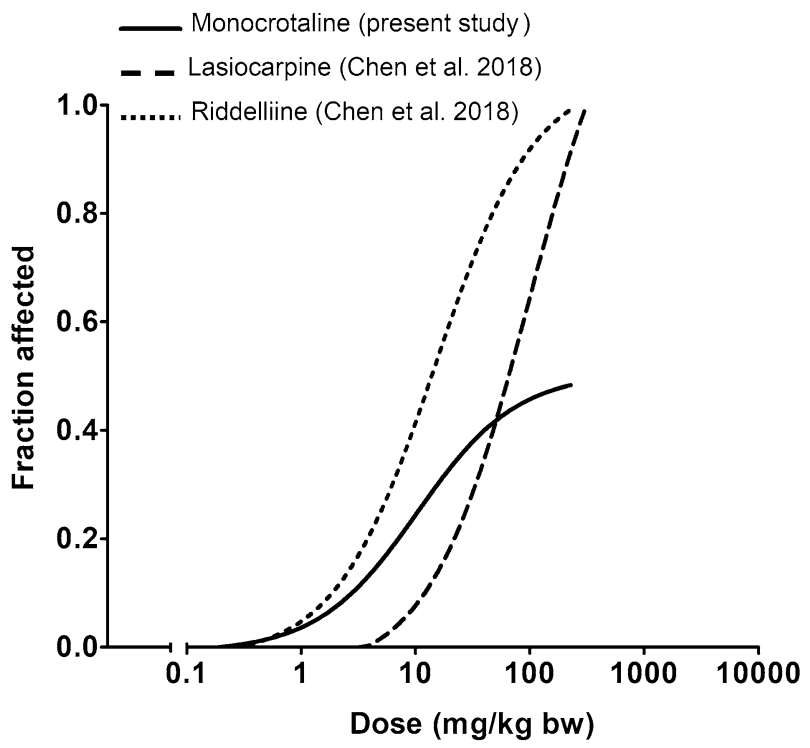

Fig. 6 Predicted in vivo dose-response curves for acute liver toxicity in rats obtained by combining in vitro data in primary rat hepatocytes and PBK modeling-based reverse dosimetry for monocrotaline (black line). For comparison, the predicted dose-response curves for liver toxicity of lasiocarpine (red line) and riddelliine (blue line) reported by Chen et al. (2018) are also presented than riddelliine and somewhat more toxic than lasiocarpine. A BMD analysis was performed on the predicted dose-response data resulting in a predicted $\mathrm{BMD}_{10}$ and range of $\mathrm{BMDL}_{10}-\mathrm{BMDU}_{10}$ values for monocrotaline, lasiocarpine, and riddelliine as presented in Table 3. The predicted $\mathrm{BMD}_{10}$ for monocrotaline appeared to be 1.1 -fold higher than that obtained from the predicted dose-response curve for riddelliine (Chen et al. 2018), while the value was 11.6 fold lower than that predicted for lasiocarpine.

Comparison of these predicted differences in in vivo toxicity to the relative differences observed in vitro (Fig. 3) shows that the differences in in vivo toxicity between monocrotaline, lasiocarpine and riddelliine were subtantially different from the differences observed in vitro where lasiocarpine and riddelliine were 35.7 and 20.7, respectively, more toxic than monocrotaline. This shift towards relatively higher toxicity for monocrotaline in the in vivo situation is due to the differences in kinetics where monocrotaline appeared to be metabolised with a catalytic efficiency that was 42.1- and 4.1-fold lower than that for lasiocarpine and riddelliine, respectively. This implies that at similar dose levels, the accompanying blood concentrations and thus toxicity will be relatively higher for monocrotaline. This result corroborates that differences in kinetics substantialy influence the relative in vivo potencies of PAs, and should not be ignored when defining relative potency factors.

\section{Comparison of the predicted PODs to PODs derived from the reported data for liver toxicity in rats}

To further evaluate the in vitro-PBK modeling-facilitated reverse dosimetry approach for prediction of monocrotaline-induced acute liver toxicity, the predicted $\mathrm{BMDL}_{10}$ for monoctotaline-induced liver toxicity was compared to the corresponding PODs (NOAEL values) derived from available in vivo studies for liver toxicity of monocrotaline in rats. Table 4 provides the overview of reported data on monocrotaline-induced acute liver toxicity in rats based on the endpoints of increased level of bound pyrrolic metabolites, increased alanine aminotransferase (ALT) activity, apoptosis of hepatic parencymal cells (HPC) and hepatic congestion (Copple et al. 2002, 2004; Lachant et al. 2018; Yan
Table 3 Predicted $\mathrm{BMDL}_{10^{-}}$ $\mathrm{BMDU}_{10}$ values derived from the dose-response curves presented in Fig. 6 predicted by PBK modeling-facilitated reverse dosimetry

\begin{tabular}{|c|c|c|c|}
\hline Compound & $\begin{array}{l}\text { Predicted } \mathrm{BMDL}_{10}-\mathrm{BMDU}_{10} \\
(\mathrm{mg} / \mathrm{kg} \text { bw/ day })\end{array}$ & $\begin{array}{l}\text { Predicted } \mathrm{BMD}_{10}(\mathrm{mg} / \mathrm{kg} \\
\text { bw/ day) }\end{array}$ & $\begin{array}{l}\text { Source of the pre- } \\
\text { dicted dose-response } \\
\text { curve }\end{array}$ \\
\hline Monocrotaline & $1.1-4.9$ & 2.8 & Present study \\
\hline Riddelliine & $1.3-3.7$ & 2.6 & (Chen et al. 2018) \\
\hline Lasiocarpine & $17.6-55.8$ & 32.5 & (Chen et al. 2018) \\
\hline
\end{tabular}


Table 4 Monocrotaline-induced liver toxicity data reported for in vivo studies in male Sprague-Dawley rats

\begin{tabular}{|c|c|c|c|c|c|c|}
\hline BW (g) & Exposure route & $\begin{array}{l}\text { Dose }(\mathrm{mg} / \mathrm{kg} \text { bw/day) } \\
\text { at single exposure }\end{array}$ & Effect & Type of POD & $\begin{array}{l}\text { POD values } \\
\text { (mg/kg bw) }\end{array}$ & Study \\
\hline $200-250$ & IP & $0 ; 65$ & $\begin{array}{l}\text { Increased level of bound } \\
\text { pyrrolic metabolites } \\
\text { levels } 24 \mathrm{~h} \text { after dosing }\end{array}$ & NOAEL (=LOAEL/10) & 6.5 & (Yan and Huxtable 1996) \\
\hline $100-130$ & IP & $0 ; 100 ; 200 ; 225 ; 300$ & $\begin{array}{l}\text { Increased plasma ALT } \\
12 \mathrm{~h} \text { after dosing }\end{array}$ & NOAEL & 100 & (Copple et al. 2002) \\
\hline $90-150$ & IP & $0 ; 300$ & $\begin{array}{l}\text { Apoptosis of HPC } 18 \mathrm{~h} \\
\text { after dosing }\end{array}$ & NOAEL (=LOAEL/10) & 30 & (Copple et al. 2004) \\
\hline$>200$ & $\mathrm{SC}$ & $0 ; 60$ & $\begin{array}{l}\text { Hepatic congestion } 24 \mathrm{~h} \\
\text { after dosing }\end{array}$ & NOAEL $(=$ LOAEL/10) & 6 & (Lachant et al. 2018) \\
\hline
\end{tabular}
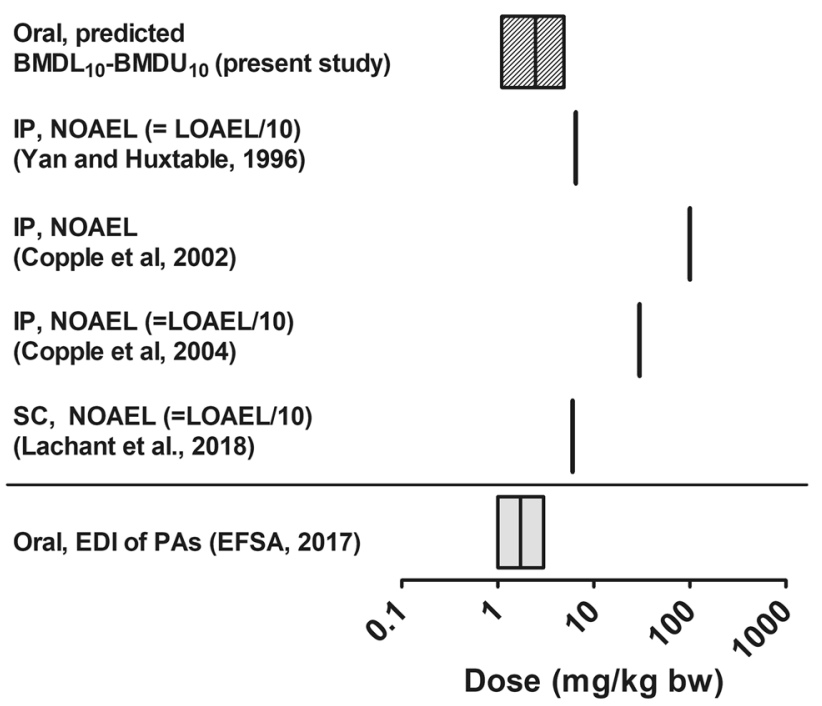

Fig. $7 \mathrm{BMDL}_{10}-\mathrm{BMDU}_{10}$ values for liver toxicity in rats predicted by the PBK modeling-facilitated reverse dosimetry approach using data for toxicity of monocrotaline in rat hepatocytes (patterned bar), compared to PODs derived from literature data on in vivo liver toxicity of monocrotaline in rats from studies with sc or ip dosing presented in Table 4 (vertical black bars). The grey bar below the line represents an oral dose range of 1-3 mg PA/kg bw/day at which acute/ shortterm adverse effect in humans may occur (EFSA 2017)

and Huxtable 1996). Since results from oral toxicity studies were not avalable, studies included in this comparison were studies with ip or sc dosing regimens. Given that the data of none of these studies enabled BMD modeling, the PODs from the available studies were based on the NOAEL or, when a NOAEL was not available, derived from the LOAEL value by assuming the NOAEL would amount to the LOAEL divided by 10 (Barnes et al. 1988) (Table 4).

Figure 7 presents a comparison of the predicted $\mathrm{BMDL}_{10}-\mathrm{BMDU}_{10}$ value of monocrotaline to the PODs data of Table 4. This comparison reveals that the reported toxicity data upon ip exposure vary substantially, and that the predicted $\mathrm{BMDL}_{10}$ value is in line with especially the NOAEL derived from the study with ip dosing reported by
Yan and Huxtable (1996) and sc dosing reported by (Lachant et al. 2018). The $\mathrm{BMDL}_{10}-\mathrm{BMDU}_{10}$ of $1.1-4.9 \mathrm{mg} / \mathrm{kg} \mathrm{bw} /$ day predicted by the in vitro-in silico approach of the present study is in line with the estimated toxic oral dose range of 1-3 mg PA/kg bw/day (EFSA 2017).

\section{Discussion}

The aim of the present study was to use an in vitro-in silico approach to predict the in vivo acute liver toxicity of monocrotaline and to characterize the influence of its metabolism on its relative in vivo toxic potency compared to lasiocarpine and riddelliine. This in vitro-in silico approach was recently shown able to predict the acute liver toxicity of lasiocarpine and riddelliine (Chen et al. 2018). The results now obtained for monocrotaline further validate the approach as a possible method to fill existing gaps in the database on PAs relevant in food. Furthermore, comparison of the results to those previously obtained for lasiocarpine and riddelliine (Chen et al. 2018) corroborated the influence of metabolism on the relative toxic potency of these three PAs.

The in vitro concentration-response data for monocrotaline-induced toxicity were obtained using primary rat hepatocytes. Primary rat hepatocytes from pooled male Sprague-Dawley rats were used because male rats were previously reported to be more sensitive towards monocrotaline toxicity than female rats (Mattocks 1972) and also because most in vivo data available for the liver toxicity of monocrotaline were obtained in male rats (Table 4). Comparison of the in vitro toxicity data to the in vitro study of Louisse et al. (2019) which showed that monocrotaline did not exhibit cytotoxicity in HepaRG cells upon $24 \mathrm{~h}$ exposure, indicates that rat hepatocytes are more sensitive to the toxicity induced by monocrotaline. This result is in line with data from Ning et al. (2019) who reported that rat hepatocytes are more sensitive towards lasiocarpine and riddelliine induced liver toxicity than HepaRG cells. Primary rat hepatocytes likely contain higher levels of the cytochrome P450 enzymes 
required for metabolism including the bioactivation of parent PAs (Ruan et al. 2014; Yao et al. 2014). In the in vitro assay with rat primary hepatocytes, the $\mathrm{IC}_{50}$ value of monocroaline was 20.7- and 35.7-fold higher than the $\mathrm{IC}_{50}$ values previously reported in the same model system for lasiocarpine and riddelliine, respectively (Chen et al. 2018). The lower toxicity of monocrotaline in in vitro liver model systems is also in line with what has been observed in other studies using HepG2 or HepaRG cells (Kusuma et al. 2014; Louisse et al. 2019).

Since in the in vitro models used the liver toxicity of monocrotaline is quantified depending on the concentration of the parent compound, which is metabolised to its toxic metabolites within the cells of the in vitro model system, the PBK model developed in the present study describes the kinetics of monocrotaline and not of its metabolites and also the reverse dosimetry is based on concentrations of the parent compound. The substrate depletion analysis indicated that monocrotaline was slowly metabolized in the incubations with rat liver and intestinal microsomes. The kinetic efficiency for monocrotaline conversion appeared to be 42.1- and 4.1-fold lower compared to that previously obtained for lasiocarpine and riddelliine, respectively, using the same approach by Chen et al. (2018). This indicates that the metabolism of monocrotaline was the lowest among these three PAs. This result is line with the study performed by Lester et al. (2019) who reported that monocrotaline is metabolically stable in the rat sandwich culture hepatocyte cell system. Marked differences in metabolic degradation among PAs was also reported recently by Geburek et al. (2019) using in vitro incubations with rat liver microsomes indicating as well that conversion of monocrotaline was lower than that of riddelliine. In the present study, these kinetic differences were taken into account when translating the concentration-response curves for in vitro toxicity to the predicted dose-response curves for acute liver toxicity using PBK model-facilitated reverse dosimetry approach.

Evaluation of the developed PBK model for monocrotaline showed that the predicted concentrations of monocrotaline in blood were in line with the kinetic data available for monocrotaline in rats (Estep et al. 1991). The PBK model used was also similar to that previously developed and evaluated for the PAs lasiocarpine and riddelliine (Chen et al. 2018). Chen et al. (2018) demonstrated that the developed PBK model could adequately predict blood concentrations of riddelliine and also adequately translate the in vitro liver toxicity induced by lasiocarpine to a predicted in vivo dose-reponse curve for liver toxicity. The results of the present study reveal that the same approach can quantitatively predict the reported in vivo acute liver toxicity of monocrotaline. The predicted $\mathrm{BMDL}_{10}$ value appeared to be in line with the NOAELs derived from availabe in vivo studies, although the comparison also revealed that especially the NOAELs derived from the reported toxicity data upon ip exposure vary substantially, in part due to the fact that the NOAELs or LOAELs were the lowest dose levels tested, leaving room for the actual LOAEL and NOAEL being lower than what has now been derived from the data. The predicted $\mathrm{BMDL}_{10}$ was in line with the NOAEL derived from the study with sc dosing reported by Lachant et al. (2018). The differences observed may in part also be ascribed to the difference in dosing regimen with the predicted values refering to oral exposure, while the in vivo were from studies with ip or sc dosing. Due to the lack of data for monocrotaline-induced acute toxicity via oral intake in rats, the predicted $\mathrm{BMDL}_{10}-\mathrm{BMDU}_{10}$ value was also compared to the oral dose range of $1-3 \mathrm{mg}$ $\mathrm{PA} / \mathrm{kg}$ bw/day at which acute/ short-term adverse effects in human are reported to occur when consuming a combination of PAs via teas or herbal infusions (EFSA 2017). The $\mathrm{BMDL}_{10}-\mathrm{BMDU}_{10}$ of $1.1-4.9 \mathrm{mg} / \mathrm{kg}$ bw/day predicted by the in vitro-in silico approach of the present study is in line with this estimated toxic oral dose level, indicating that the toxicity of monocrotaline would match the overall toxicity estimated for PAs.

The result of the present study also indicated that taking the kinetics into account the predicted in vivo differences in toxicity between monocrotaline and lasiocarpine and riddelliine appeared to be smaller than what would be predicted based on the vitro data obtained in primary hepatocytes. Comparison of the in vitro and in vivo differences in toxicity between the three PAs reveals that differences in kinetics change the relative potencies in vivo compared to those detected in vitro. The sensitivity analysis of the PBK model elucidates which parameters and thus differences between the PAs contribute to this effect. In addition to differences in metabolic clearance $\left(V_{\max }\right.$ and $\left.K_{\mathrm{m}}\right)$ also other sensitive parameters contribute. These include PL (liver/blood partition coefficient), PS (slowly perfused tissue/blood partition coefficient), and $\mathrm{Ka}$ (absorption rate for uptake from the GI tract compartment into the liver). All these parameters influence the maximum concentration $\left(C_{\max }\right)$ of monocrotaline in liver blood (Fig. 5), thereby influencing the conversion of in vitro concentrations into in vivo dose levels and thus also the effect of taking kinetics into account when converting in vitro to in vivo relative potencies. The fact that a higher PL results in a higher $C_{\max }$ implies that for compounds with equal in vitro toxicity, a higher PL will result in a shift to relatively higher in vivo toxicity at similar dose level. Conversely, a higher PS results in relatively lower $C_{\max }$ values and relatively lower toxicity at a comparable dose level. In addition, a higher Ka value resulting in a higher absorption rate for uptake from the GI tract compartment into the liver, implies that a relatively lower dose level is required to reach a similar $C_{\max }$, so that toxicity will already be observed at lower dose levels. 
Given that the sensitivity analysis ranked the partition coefficients as influential parameters on the model output, it is of interest to note that physicochemical properties, including lipophilicity, are reported to be important factors affecting the metabolic activation among PAs (Geburek et al. 2019; Mattocks 1981; Ruan et al. 2014). PAs with high lipophilicity (high $\log \mathrm{P}$ values) resulted in relatively higher levels of reactive metabolites than observed for PAs with lower $\log \mathrm{P}$ values. Using the ChemDraw 18.1 (Perkin-Elmer, USA), the log P values of lasiocarpine, riddelliine and monocrotaline amounted to $0.48,-0.26$ and -0.65 , respectively. The values of Ka derived from Eq. 5 for lasiocarpine, riddelliine and monocrotaline were $1.75 / \mathrm{h}$, 1.17/h (Chen et al. 2018), and 0.58/h, respectively. The log Papp values and Ka values derived from these $\log P$ values, which were influential parameters in the PBK model, varied in line with the order of metabolic efficiency in incubations with rat liver and intestinal microsomes being lasiocarpine $>$ riddelliine $>$ monocrotaline.

The predicted $\mathrm{BMDL}_{10}$ value for acute liver toxicity of monocrotaline obtained in the present study supports the classification of monocrotaline as a toxic PA, with a potency for acute liver toxicity that seems comparable to that of lasiocarpine and riddelliine. To what extent this conclusions also holds for the carcinogenicity of these PAs remains to be established. The conclusion of similar potency is in line with the provisional relative potency factors (pRPF) derived by Merz and Schrenk (2016) indicating that monocrotaline, as well as riddelliine is categorized as one of the most potent congeners with a pRPF similar to that of lasiocarpine of 1.0. This result is in contrast to the ranking presented by Xia et al. (2013) based on the formation of DNA adducts, who ranked monocrotaline as group II with moderate tumour formation. Louisse et al. (2019) classified monocrotaline into group 3 with an pRPF of 0.06 based on its in vitro $\gamma \mathrm{H} 2 \mathrm{AX}$ induction potency in the human liver cell line HepaRG, while lasiocarpine and ridddelliine were categorized as group 1 with a pRPF of 1.08 and 1, respectively. However, these in vitro studies are based on different endpoint and also do not take potential differences in in vivo toxicokinetics into account, while the result of the present study clearly indicate that this will hamper the translation of in vitro RPFs to the in vivo situation. The lower metabolic clearance of monocrotaline than of lasiocarpine and riddelliine observed in the present study is in line with the results from Lester et al. (2019) and Geburek et al. (2019), and will result in higher relative in vivo concentrations and potential toxicity than predicted based on in vitro concentration-response curves.

In conclusion, the results of the present study illustrate that a combined in vitro-in silico approach can be used to obtain insights in monocrotaline-induced acute liver toxicity in rats. Furthermore, the comparison of its relative toxic potency to lasiocarpine and riddelliine indicates that the kinetic and metabolic properties of these PAs should be taken into account when defining relative differences in in vivo toxic potency. It is of relevance to note that the PBK model based reverse dosimetry was based on the parent compound. The predicted in vivo data obtained include both the relative differences in bioactivation (included in the in vitro toxicity data) and the relative differences in clearance of the parent compound (included via the PBK model). In the present study on monocrotaline, and our previous studies on lasiocarpine and riddelliine (Chen et al. 2018), the PBK model parameters for metabolic clearance were obtained using incubations with rat liver microsomes. Use of primary rat hepatocytes would have been an alternative and adequate approach but would less well match with our ultimate aim to contribute to the 3Rs (Replacement, Reduction and Refinement) for animal testing. This insight can be used to obtain a promising alternative testing strategy in risk and safety evaluation of PAs.

Acknowledgements This research was supported by a grant from the Indonesian Endowment Fund for Education, Ministry of Finance, Republic of Indonesia through a Beasiswa Pendidikan Indonesia Lembaga Pengelola Dana Pendidikan (BPI LPDP) doctoral scholarship [Grant Number: PRJ-365/LPDP/2016] awarded to Suparmi.

Author contributions SS performed the research. SW technically helped in LC-MS analysis. SS and IR designed the research study. SS and SW analyzed the data. SS, SW and IR wrote and edited the manuscript.

\section{Complaince with ethical standards}

Conflict of interest The authors state no conflicts of interest.

Open Access This article is licensed under a Creative Commons Attribution 4.0 International License, which permits use, sharing, adaptation, distribution and reproduction in any medium or format, as long as you give appropriate credit to the original author(s) and the source, provide a link to the Creative Commons licence, and indicate if changes were made. The images or other third party material in this article are included in the article's Creative Commons licence, unless indicated otherwise in a credit line to the material. If material is not included in the article's Creative Commons licence and your intended use is not permitted by statutory regulation or exceeds the permitted use, you will need to obtain permission directly from the copyright holder. To view a copy of this licence, visit http://creativecommons.org/licenses/by/4.0/.

\section{References}

Adams R, Rogers EF (1939) The structure of monocrotaline, the alkaloid in Crotalaria spectabilis and Crotalaria retusa I. J Am Chem Soc 61(10):2815-2819. https://doi.org/10.1021/ja01265a073

Agents Classified by the IARC Monographs, Volumes 1-125 (2019) International Agency for Research on Cancer. https://monographs .iarc.fr/agents-classified-by-the-iarc/. Accessed 6 December 2019

Barnes DG, Dourson M, Dourson M et al (1988) Reference dose (RfD): Description and use in health risk assessments. Regul 
Toxicol Pharmacol 8(4):471-486. https://doi.org/10.1016/02732300(88)90047-5

Brown RP, Delp MD, Lindstedt SL, Rhomberg LR et al (1997) Physiological parameter values for physiologically based pharmacokinetic models. Toxicol Ind Health 13:407-484. https://doi. org/10.1177/074823379701300401

Bull LB, Culvenor Ct, Dick A (1968) The pyrrolizidine alkaloids: their chemistry, pathogenicity and other biological properties. QRB 45(1):67. https://doi.org/10.1086/406383

Butler WH, Mattocks AR, Barnes AJM (1970) Lesions in the liver and lungs of rats given pyrrole derivatives of pyrrolizidine alkaloids. J Pathol 100(3):169-175. https://doi.org/10.1002/path.1711000305

Chen L, Ning J, Louisse J, Wesseling S, Rietjens IMCM (2018) Use of physiologically based kinetic modelling-facilitated reverse dosimetry to convert in vitro cytotoxicity data to predicted in vivo liver toxicity of lasiocarpine and riddelliine in rat. Food Chem Toxicol 116:216-226. https://doi.org/10.1016/j.fct.2018.04.012

Copple BL, Banes A, Ganey PE, Roth RA (2002) Endothelial cell injury and fibrin deposition in rat liver after monocrotaline exposure. Toxicol Sci 65(2):309-318. https://doi.org/10.1093/toxsc i/65.2.309

Copple BL, Rondelli CM, Maddox JF, Hoglen NC, Ganey PE, Roth RA (2004) Modes of cell death in rat liver after monocrotaline exposure. Toxicol Sci 77(1):172-182. https://doi.org/10.1093/ toxsci/kfh011

Couet CE, Hopley J, Hanley AB (1996) Metabolic activation of pyrrolizidine alkaloids by human, rat and avocado microsomes. Toxicon Off J Int Soc Toxinol 34(9):1058-1061. https://doi. org/10.1016/0041-0101(96)00056-6

Cubitt HE, Houston JB, Galetin A (2009) Relative importance of intestinal and hepatic glucuronidation-impact on the prediction of drug clearance. Pharm Res 26(5):1073. https://doi.org/10.1007/ s11095-008-9823-9

DeJongh J, Verhaar HJM, Hermens JLM (1997) A quantitative property-property relationship (QPPR) approach to estimate in vitro tissue-blood partition coefficients of organic chemicals in rats and humans. Arch Toxicol 72(1):17-25. https://doi.org/10.1007/s0020 40050463

EFSA-Scientific-Committee, Anthony H, Diane B, et al. (2017) Update: use of the benchmark dose approach in risk assessment. EFSA J 15(1):e04658. https://doi.org/10.2903/j.efsa.2017.4658

EFSA (2011) Scientific opinion on pyrrolizidine alkaloids in food and feed. EFSA J 9(11):2406. https://doi.org/10.2903/j.efsa.2011.2406

EFSA (2017) Risks for human health related to the presence of pyrrolizidine alkaloids in honey, tea, herbal infusions and food supplements. EFSA J 15(7):e04908. https://doi.org/10.2903/j. efsa.2017.4908

Estep JE, Lame MW, Morin D, Jones AD, Wilson DW, Segall HJ (1991) $\left[{ }^{14} \mathrm{C}\right]$ monocrotaline kinetics and metabolism in the rat. Drug Metab Dispos 19(1):135-9. https://dmd.aspetjournals.org/ content/19/1/135.long

Evans MV, Andersen ME (2000) Sensitivity analysis of a physiological model for 2,3,7,8-tetrachlorodibenzo-p-dioxin (TCDD): Assessing the impact of specific model parameters on sequestration in liver and fat in the rat. Toxicol Sci 54(1):71-80. https://doi. org/10.1093/toxsci/54.1.71

Evans DF, Pye G, Bramley R, Clark AG, Dyson TJ, Hardcastle JD (1988) Measurement of gastrointestinal $\mathrm{pH}$ profiles in normal ambulant human subjects. Gut 29(8):1035-1041. https://doi. org/10.1136/gut.29.8.1035

Fu PP (2017) Pyrrolizidine alkaloids: Metabolic activation pathways leading to liver tumor initiation. Chem Res Toxicol 30(1):81-93. https://doi.org/10.1021/acs.chemrestox.6b00297

Fu PP, Xia Q, Lin G, Chou MW (2004) Pyrrolizidine Alkaloidsgenotoxicity, metabolism enzymes, metabolic activation, and mechanisms. Drug Metab Rev 36(1):1-55. https://doi. org/10.1081/dmr-120028426

Geburek I, Preiss-Weigert A, Lahrssen-Wiederholt M, Schrenk D, These A (2019) In vitro metabolism of pyrrolizidine alkaloidsmetabolic degradation and GSH conjugate formation of different structure types. Food Chem Toxicol. https://doi.org/10.1016/j. fct.2019.110868

Gomez-Arroyo JG, Farkas L, Alhussaini AA et al (2012) The monocrotaline model of pulmonary hypertension in perspective. Am J Physio Lung Cell Mol Physiol 302(4):L363-L369. https://doi. org/10.1152/ajplung.00212.2011

Hou TJ, Zhang W, Xia K, Qiao XB, Xu XJ (2004) ADME evaluation in drug discovery. 5. Correlation of Caco-2 permeation with simple molecular properties. J Chem Inf Comput Sci 44(5):1585-1600. https://doi.org/10.1021/ci049884m

Koepsell H, Endou H (2004) The SLC22 drug transporter family. Pflügers Archiv 447(5):666-676. https://doi.org/10.1007/s0042 4-003-1089-9

Kusuma SS, Tanneeru K, Didla S, Devendra BN, Kiranmayi P (2014) Antineoplastic activity of monocrotaline against hepatocellular carcinoma. Anticancer Agents Med Chem 14(9):1237-1248. https ://doi.org/10.2174/1871520614666140715085907

Lachant DJ, Meoli DF, Haight D, Lyons JA, Swarthout RF, White RJ (2018) Low dose monocrotaline causes a selective pulmonary vascular lesion in male and female pneumonectomized rats. Exp Lung Res 44(1):51-61. https://doi.org/10.1080/01902 148.2017.1422157

Lafranconi MW, Huxtable RJ (1984) Hepatic metabolism and pulmonary toxicity of monocrotaline using isolated perfused liver and lung. Biochem Pharmacol 33(15):2479-2484. https://doi. org/10.1016/0006-2952(84)90721-4

Lester C, Troutman J, Obringer C et al (2019) Intrinsic relative potency of a series of pyrrolizidine alkaloids characterized by rate and extent of metabolism. Food Chem Toxicol 131:110523. https:// doi.org/10.1016/j.fct.2019.05.031

Li N, Xia Q, Ruan J, Fu PP, Lin G (2011) Hepatotoxicity and tumorigenicity induced by metabolic activation of pyrrolizidine alkaloids in herbs. Curr Drug Metab 12(9):823-834. https://doi. org/10.2174/138920011797470119

Li W, Wang K, Lin G, Peng Y, Zheng J (2016) Lysine adduction by reactive metabolite(s) of monocrotaline. Chem Res Toxicol 29(3):333-341. https://doi.org/10.1021/acs.chemrestox.5b00488

Louisse J, Rijkers D, Stoopen G et al (2019) Determination of genotoxic potencies of pyrrolizidine alkaloids in HepaRG cells using the $\gamma \mathrm{H} 2 \mathrm{AX}$ assay. Food Chem Toxicol 131:110532. https://doi. org/10.1016/j.fct.2019.05.040

Lu Y, Ma J, Song Z, Ye Y, Fu PP, Lin G (2018) The role of formation of pyrrole-ATP synthase subunit beta adduct in pyrrolizidine alkaloid-induced hepatotoxicity. Arch Toxicol 92(11):3403-3414. https://doi.org/10.1007/s00204-018-2309-6

Martignoni M, Groothuis GMM, de Kanter R (2006) Species differences between mouse, rat, dog, monkey and human CYP-mediated drug metabolism, inhibition and induction. Exp Opin Drug Metab Toxicol 2(6):875-894. https://doi.org/10.1517/17425255.2.6.875

Mattocks AR (1968) Toxicity of pyrrolizidine alkaloids. Nature 217(5130):723-728. https://doi.org/10.1038/217723a0

Mattocks AR (1972) Acute hepatotoxicity and pyrrolic metabolites in rats dosed with pyrrolizidine alkaloids. Chem Biol Interact 5(4):227-242. https://doi.org/10.1016/0009-2797(72)90027-0

Mattocks AR (1981) Relation of structural features to pyrrolic metabolites in livers of rats given pyrrolizidine alkaloids and derivatives. Chem Biol Interact 35(3):301-310. https://doi.org/10.1016/00092797(81)90005-3

McConnell EL, Basit AW, Murdan S (2008) Measurements of rat and mouse gastrointestinal $\mathrm{pH}$, fluid and lymphoid tissue, and 
implications for in-vivo experiments. J Pharm Pharmacol 60(1):63-70. https://doi.org/10.1211/jpp.60.1.0008

Medinsky MA, Leavens TL, Csanády GA, Gargas ML, Bond JA (1994) In vivo metabolism of butadiene by mice and rats: a comparison of physiological model predictions and experimental data. Carcinogenesis 15(7):1329-1340. https://doi.org/10.1093/carci $\mathrm{n} / 15.7 .1329$

Merz K-H, Schrenk D (2016) Interim relative potency factors for the toxicological risk assessment of pyrrolizidine alkaloids in food and herbal medicines. Toxicol Lett 263:44-57. https://doi. org/10.1016/j.toxlet.2016.05.002

Mohabbat O, Shafiq Younos M, Merzad AA, Srivastava RN, Ghaos Sediq G, Aram GN (1976) An Outbreak of hepatic veno-occlusive disease in North-Western Afghanistan. The Lancet 308(7980):269-271. https://doi.org/10.1016/S0140 -6736(76)90726-1

Newberne PM, Rogers AE (1973) Nutrition, monocrotaline, and aflatoxin B1 in liver carcinogenesis. Plant Foods Man 1(1):23-31. https://doi.org/10.1080/03062686.1973.11904153

Ning J, Chen L, Strikwold M, Louisse J, Wesseling S, Rietjens IMCM (2019) Use of an in vitro-in silico testing strategy to predict interspecies and inter-ethnic human differences in liver toxicity of the pyrrolizidine alkaloids lasiocarpine and riddelliine. Arch Toxicol. https://doi.org/10.1007/s00204-019-02397-7

Pearce R, Greenway D, Parkinson A (1992) Species differences and interindividual variation in liver microsomal cytochrome $\mathrm{P} 450$ 2A enzymes: effects on coumarin, dicumarol, and testosterone oxidation. Arch Biochem Biophys 298(1):211-225. https://doi. org/10.1016/0003-9861(92)90115-D

Reid MJ, Lamé MW, Morin D, Wilson DW, Segall HJ (1998) Involvement of cytochrome $\mathrm{P} 4503 \mathrm{~A}$ in the metabolism and covalent binding of ${ }^{14} \mathrm{C}$-monocrotaline in rat liver microsomes. J Biochem Mol Toxicol 12(3):157-166. https://doi.org/10.1002/ (SICI)1099-0461(1998)12:3<157::AID-JBT4>3.0.CO;2-K

Ruan J, Yang M, Fu P, Ye Y, Lin G (2014) Metabolic activation of pyrrolizidine alkaloids: insights into the structural and enzymatic basis. Chem Res Toxicol 27(6):1030-1039. https://doi. org/10.1021/tx500071q

Schultze AE, Roth RA (1998) Chronic pulmonary hypertension-the monocrotaline model and involvement of the hemostatic system. J Toxicol Environ Health Part B 1(4):271-346. https://doi. org/10.1080/10937409809524557

Shumaker RC, Robertson KA, Hsu IC, Allen JR (1976) Neoplastic transformation in tissues of rats exposed to monocrotaline or dehydroretronecine23. JNCI J Natl Cancer Inst 56(4):787-790. https://doi.org/10.1093/jnci/56.4.787

Tandon BN, Tandon HD, Tandon RK, Narndranathan M, Joshi YK (1976) An epidemic of veno-occlusive disease of liver iIn Central India. The Lancet 308(7980):271-272. https://doi.org/10.1016/ S0140-6736(76)90727-3

Tu M, Sun S, Wang K et al (2013) Organic cation transporter 1 mediates the uptake of monocrotaline and plays an important role in its hepatotoxicity. Toxicology 311(3):225-230. https://doi. org/10.1016/j.tox.2013.06.009

Tu M, Li L, Lei H et al (2014) Involvement of organic cation transporter 1 and CYP3A4 in retrorsine-induced toxicity. Toxicology 322:34-42. https://doi.org/10.1016/j.tox.2014.04.007 van Liempd S, Morrison D, Sysmans L, Nelis P, Mortishire-Smith R (2011) Development and validation of a higher-throughput equilibrium dialysis assay for plasma protein binding. JALA J Assoc Lab Autom 16(1):56-67. https://doi.org/10.1016/j. jala.2010.06.002

Wang J, Yang L, Wang C, Wang Z (2009) The action of cytochrome p450 enzymes and flavin-containing monooxygenases on the $\mathrm{N}$-oxide of pyrrolizidine alkaloid monocrotaline. Asian J Trad Med 4(2):41-50. https://www.researchgate.net/publication/26640 5093

Wang C, Li Y, Gao J et al (2011) The comparative pharmacokinetics of two pyrrolizidine alkaloids, senecionine and adonifoline, and their main metabolites in rats after intravenous and oral administration by UPLC/ESIMS. Anal Bioanal Chem 401(1):275-287. https:// doi.org/10.1007/s00216-011-5075-3

Waters NJ, Jones R, Williams G, Sohal B (2008) Validation of a rapid equilibrium dialysis approach for the measurement of plasma protein binding. J Pharm Sci 97(10):4586-4595. https://doi. org/10.1002/jps.21317

Xia Q, Zhao Y, Von Tungeln LS et al (2013) Pyrrolizidine alkaloidderived DNA adducts as a common biological biomarker of pyrrolizidine alkaloid-induced tumorigenicity. Chem Res Toxicol 26(9):1384-1396. https://doi.org/10.1021/tx400241c

Xia Q, He X, Ma L, Chen S, Fu PP (2018) Pyrrolizidine alkaloid secondary pyrrolic metabolites construct multiple activation pathways leading to DNA adduct formation and potential liver tumor initiation. Chem Res Toxicol 31(7):619-628. https://doi. org/10.1021/acs.chemrestox.8b00096

Yan CC, Huxtable RJ (1995) The relationship between the concentration of the pyrrolizidine alkaloid monocrotaline and the pattern of metabolites released from the isolated liver. Toxicol Appl Pharmacol 130(1):1-8. https://doi.org/10.1006/taap.1995.1001

Yan CC, Huxtable RJ (1996) Effects of monocrotaline, a pyrrolizidine alkaloid, on glutathione metabolism in the rat. Biochem Pharmacol 51(3):375-379. https://doi.org/10.1016/0006-2952(95)02189 $-2$

Yang X, Li W, Sun Y et al (2017) Comparative study of hepatotoxicity of pyrrolizidine alkaloids retrorsine and monocrotaline. Chem Res Toxicol 30(2):532-539. https://doi.org/10.1021/acs.chemrestox $.6 \mathrm{~b} 00260$

Yao J, Li C-g, Gong L-k et al (2014) Hepatic cytochrome P450s play a major role in monocrotaline-induced renal toxicity in mice. Acta Pharmacol Sin 35(2):292-300. https://doi.org/10.1038/ aps.2013.145

Zuber R, Anzenbacherová E, Anzenbacher P (2002) Cytochromes P450 and experimental models of drug metabolism. J Cell Mol Med 6(2):189-198. https://doi.org/10.1111/j.1582-4934.2002.tb001 86.x

Publisher's Note Springer Nature remains neutral with regard to jurisdictional claims in published maps and institutional affiliations. 